\title{
Psychometric Evaluation of the Japanese Wijma Delivery Expectancy/Experience Questionnaire Version B
}

\section{Mizuki Takegata', Megumi Haruna'2, Masayo Matsuzaki², Mie Shiraishi², Tadaharu Okano³, Elisabeth Severinsson 4}

\author{
${ }^{1}$ Department of Paediatric Infectious Diseases, Institute of Tropical Medicine, Nagasaki University, Nagasaki, Japan \\ ${ }^{2}$ Department of Midwifery and Women's Health, Division of Health Sciences \& Nursing Graduate School of Medicine, \\ University of Tokyo, Tokyo, Japan \\ ${ }^{3}$ Centre of Physical and Mental Health, Mie University, Tsu, Japan \\ ${ }^{4}$ Centre for Women's, Family \& Child Health, Department of Nursing Science, Faculty of Health Sciences, University College of \\ Southeast Norway, Kongsberg, Norway
}

Email: mharuna-tky@umin.ac.jp

How to cite this paper: Takegata, M., Haruna, M., Matsuzaki, M., Shiraishi, M., Okano, T. and Severinsson, E. (2017) Psychometric Evaluation of the Japanese Wijma Delivery Expectancy/Experience Questionnaire Version B. Open Journal of Nursing, 7, 15-27.

http://dx.doi.org/10.4236/ojn.2017.71002

Received: November 22, 2016

Accepted: January 10, 2017

Published: January 13, 2017

Copyright (ㅇ 2017 by authors and Scientific Research Publishing Inc. This work is licensed under the Creative Commons Attribution International License (CC BY 4.0).

http://creativecommons.org/licenses/by/4.0/

\begin{abstract}
The Wijma Delivery Expectancy/Experience Questionnaire (W-DEQ) is a widely accepted approach to measuring fear of childbirth and is available in two versions: antenatal (version A) and postnatal (version B). The aim of this study was to develop the Japanese W-DEQ version B and confirm its validity and reliability among Japanese women. A self-administered questionnaire incorporating the translated Japanese W-DEQ (JW-DEQ) version B and the anxiety subscale of the Hospital Anxiety and Depression Scale (HADS) was distributed to Japanese mothers at two days postpartum. Of the 246 women recruited, 231 who completed the questionnaire at two days postpartum were analyzed. An exploratory factor analysis of the JW-DEQ version B revealed four factors: fear, lack of positive anticipation, isolation and riskiness. The JW-DEQ version B exhibited a positive correlation with the HADS anxiety subscale $(\mathrm{r}=0.34, \mathrm{p}<0.001)$. The Cronbach's $\alpha$ value derived from the total 33 items was 0.95 . This study provides evidence of the factorial, concurrent validity and the internal consistency of the JW-DEQ version B. However, a further study involving participants from different demographic groups will be required.
\end{abstract}

\section{Keywords}

Japanese Women, Reliability, Scale Development, Postnatal Fear of Childbirth, Validity 


\section{Introduction}

Women may have both positive and negative recognition giving birth. A negative experience caused by fear during birth (postnatal fear of childbirth) [1] includes concern about pain, unexpected complications such as a difficult course of labour, emergency Caesarean section, isolation during labour and loss of control [2]. Women are afraid of pain and the uncertainty of the delivery process (fear), leading to worry about being in an uncontrollable situation and alone (isolation), which can lower their confidence and evoke a sense of failure [2]. Another concern is the possible risks to their own health, such as bleeding or obstetric interventions, or to the health of their child, for example, physical injury or severe distress (riskiness) [3].

When women experience severe fear during birth, childbirth is often described as "being in an unavoidable situation without return, which was demanding for both control and loss of control" or as an "uncontrollable situation not in agreement with the expectation", which generates a long term negative memory of the birth experience [3]. Such women are more likely to exhibit emotional irritability and may have postnatal traumatic stress symptoms [4]. These women suffer involuntary flashbacks of the traumatic birth (Intrusion) in their daily life or have nightmares related to birth, making them try to avoid situations or thoughts that remind them of the birth [5]. In addition, they might also experience difficulty recalling key features (alterations in arousal) and have a persistent negative feeling about themselves and others [5]. Furthermore, it has been reported that women who had a negative and traumatic experience of childbirth are reluctant to have another child [6]. Therefore, assessing mothers' experience of "fear of birth" in the early stage of the postpartum period and providing appropriate support are very important for life after discharge from the hospital.

One of key factors in severe fear of childbirth is an "abnormal course of delivery", such as an emergency Caesarean section, vacuum delivery, induced delivery or foetal distress during labour, all of which increase postnatal fear of childbirth [7]. Another key factor might be a severe fear of childbirth during pregnancy. The present authors examined the association between antenatal and postnatal fear of childbirth, taking birth related factors (duration of labour, instrumental delivery and emergency Caesarean section) into account by means of Structural equation modelling (SEM) [8]. The results revealed that antenatal fear of childbirth was the most significant predictor of postnatal fear of childbirth (Primiparas: $\beta=0.58, \mathrm{p}=0.002$; Multiparas: $\beta=0.62, \mathrm{p}<0.001$ ). Because there are only a few cases of emergency Caesarean section in the study, we are unable to prove that antenatal fear of childbirth is the most significant predictor. However, our findings demonstrated that pregnant women who are severely afraid of the upcoming childbirth are more likely to consider their childbirth experiences more frightening than others, even when the course of delivery is normal [8]. Thus, the result indicated that it may be essential to identify and support pregnant women with severe fear of childbirth in order to reduce the risk of emo- 
tional disorders during the postnatal period [8]. Assessing postnatal fear of childbirth would not only be helpful for early detection of a negative birth experience caused by abnormal delivery but also for evaluating antenatal and intrapartum midwifery care in clinical settings.

Because of the lack of a Japanese scale that can assess both antenatal and postnatal fear of childbirth, we began developing validated Japanese scales in 2011. The Wijma Delivery Expectancy/Experience Questionnaire (W-DEQ) [1], which has been validated in English, Italian and Turkish besides the original Swedish version, is widely used in several countries [9] [10] [11]. The W-DEQ comprises two versions: version $A$, which assesses antenatal fear of childbirth (expectations), and version $B$, which assesses postnatal fear of childbirth (experience) [1]. To the best of our knowledge, the $\mathrm{W}-\mathrm{DEQ}$ version $\mathrm{B}$ is a validated and reliable measure in other language versions [9] [10] [11]. The scale demonstrates high concurrent validity, a significant correlation with anxiety, depression and neuroticism [9] [11], as well as high internal consistency (Cronbach's $\alpha$ = 0.87) [1] [9]. However, most researchers use the $\mathrm{W}-\mathrm{DEQ}$ version $\mathrm{B}$ without examining its factor structure because they consider that the psychometric structure of version $\mathrm{A}$ and $\mathrm{B}$ is homogenous (fear, lack of anticipation, isolation and riskiness) due to the items being identical [1] [11]. Only one study [12] contained a factor analysis that revealed the six factor structure of the Turkish W-DEQ version B (concerns about pain, lack of positive behaviours, loneliness, lack of positive feelings, concerns about childbirth and concerns about the baby) [1]. Because no previous study examined the psychometric aspects of the Japanese $\mathrm{W}$-DEQ version $\mathrm{B}$, information concerning the validation of the scale would provide more evidence that the $\mathrm{W}-\mathrm{DEQ}$ can serve as a standard measure.

The aim of the present study was to develop the Japanese W-DEQ version B and explore its validity and reliability among Japanese women.

\section{Methods}

\subsection{Translation and Comprehensiveness}

We translated the W-DEQ version B into Japanese in accordance with the guidelines presented by Wild et al. (2005) [13]. First, forward translation from the original Swedish into Japanese was made by a qualified translator, who is a native Japanese proficient in the Swedish. The appropriateness of the translated text in a Japanese cultural context was then discussed by the Japanese researchers, who have a midwifery background. If any reformulation was deemed necessary, the forward translator was requested to revise the item in question. Second, back translation from Japanese into Swedish was made by two different Japanese translators who are also proficient in the Swedish language. The researchers then examined the similarity between the original and back-translated Swedish versions to determine the accuracy of the translation. Third, a pilot test was conducted to explore possible alternative formulations, as well as confirm the understand ability of the scale and the accuracy of its interpretation. Ten pregnant women who were 37 gestational weeks at an obstetric clinic in Tokyo were asked 
to fill in the questionnaire (July, 2011). The total time required to fill in the scale ranged between three and seven minutes. Finally, the researchers asked the original author for approval of the translation process and the final JW-DEQ version B.

\subsection{Study Protocol}

The present study was conducted in parallel with the translation of the JW-DEQ version A [14]. Healthy Japanese women at 37 gestational weeks were recruited between July and November 2011 at an obstetric clinic in Tokyo. The clinic only provides delivery without anaesthesia. Women can choose their preferred birth position during labour. The exclusion criteria were; inability to understand Japanese, teenagers and women hospitalised due to a major complication, who require special ethical consideration. Cases of planned Caesarean section were excluded because the original W-DEQ is not suitable for women who did not experience labour. Two hundred and forty six women were invited to participate by a researcher (M.T.) at the outpatient department. A total of 240 agreed and filled (97\%) in the first questionnaire at 37 weeks gestation [14]. Sociodemographic information including age, educational background, in addition to medical information such as a history of mental disorders, complications during pregnancy (pregnancy-induced hypertension, threatened premature labour and placenta praevia) and foetal anomalies (intrauterine growth restriction and foetal malformation) were collected from their medical record. On the second day postpartum the participants were given another questionnaire by the researcher (M.T.) to assess the validity and reliability of the JW-DEQ version B. With regard to subjective birth experiences, as most women synthesize their childbirth experiences on around the third day after delivery when they recover from the physical fatigue caused by childbirth [15], the authors considered the third day to be the best time to ask the mothers to fill in the questionnaire. A maximum of 15 minutes was required to fill in the first questionnaire, including the psychological scales to examine the validity of the $\mathrm{W}-\mathrm{DEQ}$ version A [14]. The time required for the second questionnaire was five minutes.

\subsection{Psychometric Measures}

\subsubsection{JW-DEQ Version $B$}

Postnatal fear of childbirth (experience) was assessed by the JW-DEQ version B [1] [14], which comprises 33 items rated on a six-point scale; "Not at all" (0) to "Extremely" (5). The total score ranges from 0 to 165 . Higher scores show a greater degree of fear, with scores over 85 indicating severe fear of childbirth [1]. The Cronbach's $\alpha$ value was 0.95 as stated by Wijma et al. (1998) [1].

\subsubsection{The Hospital Anxiety and Depression Scale (HADS)}

General symptoms caused by dysphoric mood were assessed by the Hospital Anxiety and Depression Scale (HADS) [16] [17]. The HADS comprises 14 items with two subscales: the anxiety subscale (seven items) and the depression subscale (seven items). The HADS is a valid and reliable measure for assessing gen- 
eral anxiety and depression without considering physical symptoms [16], which might be due to hormonal change during the postnatal period. As the HADS contains less items for assessing anxiety and depression than other validated measures such as the Spielberger State Trait Inventory (STAI, 20 items) [18], the authors decided to use it in order to minimize the effort required by the mothers at early postpartum. The items in each subscale were on a four-point scale ranging from "strongly disagree" (1) to "strongly agree" (4) yielding possible scores from seven to 28 , with a higher score indicating a greater level of general anxiety and depression. Because fear is defined as "the unpleasant emotional state consisting of psychological and psychophysiological responses to a real external threat or danger [19]", fear and anxiety are similar in meaning. Therefore, it can be hypothesized that the JW-DEQ version B has a moderate correlation with the HADS anxiety subscale. In this study, the HADS anxiety subscale was used for concurrent validation. The Cronbach's $\alpha$ was 0.73 for the anxiety subscale in the present study.

\subsection{Statistical Analysis}

A minimum sample of 165 women is required to provide the necessary five to ten cases per item for an exploratory factor analysis (EFA) [20]. The factor structure of the total number of items was explored by means of EFA and the robust maximum likelihood estimation procedure employed. Firstly, the factors with eigenvalues above one were identified by means of scree plots. Secondly, a promax rotation was performed.

The total and factor scores of the JW-DEQ version B and the HADS subscale scores were correlated by means of the Pearson product-moment correlation coefficients (concurrent validity). The correlation coefficient (r) scores were classified as weak (0.10 - 0.29), moderate (0.30 - 0.49), or high (0.50) [21]. The Cronbach's $\alpha$ coefficient was calculated (internal validity) and 0.7 was set as a minimum criterion for acceptance [22]. All tests were two-tailed and $P$-values of 0.05 were deemed statistically significant. The SPSS version 22.0 was used for analyses.

\subsection{Ethical Approval}

The study was approved by the Ethics Committee of the Graduate School of Medicine at the University of Tokyo, Tokyo, Japan (No. 3417, 2011). All participants were informed about the study, assured of anonymity and confidentiality, as well as the fact that they could withdraw at any time by making a written request.

\section{Results}

\subsection{Characteristics of Participants}

Table 1 presents the characteristics of the participants. Two hundred and thirty-three women out of the 240 who agreed to participate (96\%) returned the questionnaire early postpartum. Excluding two participants whose data was one 
missing of the JW-DEQ version B item, 231 were analyzed (primiparas, $\mathrm{n}=115$, multiparas, $\mathrm{n}=116$ ). Their average age was 32 years (standard deviation $[\mathrm{SD}]=$ 3.98). The majority $(n=139,60 \%)$ had graduated from university. Six out of the 231 women $(2 \%)$ had a history of depression or panic disorder but were not on medication at the time of the study. Seven women had an emergency Caesarean section (3\%), 15 women had a vacuum delivery (6\%) and 58 women had an induced delivery (25\%). The average score of version B in the present study was $53.06(\mathrm{SD}=28.58)$. In primiparas, the average score of version $\mathrm{B}$ was 63.78 ( $\mathrm{SD}$ $=27.33)$, while in multiparas it was $42.3(\mathrm{SD}=25.75)(p<0.001)$.

\subsection{Factorial Validity}

The EFA (Table 2) revealed a four-factor structure, which is presented visually by means of a scree plot, although five factors had an eigenvalue greater than

Table 1. Participants' characteristics.

\begin{tabular}{|c|c|c|c|c|c|c|c|c|}
\hline & \multicolumn{2}{|c|}{ Total $(\mathrm{n}=231)$} & \multicolumn{2}{|c|}{$\begin{array}{c}\text { Nulliparas } \\
(\mathrm{n}=115)\end{array}$} & \multicolumn{2}{|c|}{$\begin{array}{c}\text { Multiparas } \\
(\mathrm{n}=116)\end{array}$} & \multirow{2}{*}{\multicolumn{2}{|c|}{$p$-value }} \\
\hline & \multicolumn{2}{|c|}{ Mean \pm SD or $\mathrm{n}(\%)$} & \multicolumn{2}{|c|}{ Mean \pm SD or $n(\%)$} & \multicolumn{2}{|c|}{ Mean \pm SD or $\mathrm{n}(\%)$} & & \\
\hline \multicolumn{9}{|l|}{ Demographic data } \\
\hline Age & 32.97 & \pm 3.98 & 32.01 & \pm 4.10 & 33.94 & \pm 3.75 & $<0.001$ & a \\
\hline $\begin{array}{c}\text { Education high } \\
\text { school }\end{array}$ & 16 & (7) & 6 & (5) & 10 & (8) & 0.653 & $\mathrm{~b}$ \\
\hline College & 76 & (33) & 41 & (35) & 35 & $(30)$ & & \\
\hline University & 139 & (60) & 69 & $(60)$ & 70 & $(60)$ & & \\
\hline $\begin{array}{l}\text { Planning to deliver } \\
\text { with family }\end{array}$ & 225 & $(97)$ & 112 & $(97)$ & 113 & (97) & 0.512 & $\mathrm{~b}$ \\
\hline $\begin{array}{l}\text { History of psychiatric } \\
\text { disorders }\end{array}$ & 6 & (3) & 4 & (3) & 2 & (2) & 0.252 & c \\
\hline $\begin{array}{l}\text { Complexity of } \\
\text { pregnancy }\end{array}$ & 37 & $(16)$ & 20 & $(17)$ & 17 & $(15)$ & 0.375 & $\mathrm{~b}$ \\
\hline $\begin{array}{c}\text { Anomalies in } \\
\text { development of foetus }\end{array}$ & 7 & (3) & 4 & (3) & 3 & (3) & 0.363 & c \\
\hline \multicolumn{9}{|l|}{ Birth outcomes } \\
\hline $\begin{array}{l}\text { Duration of } \\
\text { labour }(\mathrm{h})\end{array}$ & 6.37 & \pm 4.57 & 8.00 & \pm 5.09 & 4.00 & \pm 3.00 & $<0.001$ & a \\
\hline $\begin{array}{c}\text { Emergency } \\
\text { Caesarean Section }\end{array}$ & 7 & (3) & 7 & (6) & 0 & $(0)$ & 0.010 & c \\
\hline Vacuum delivery & 15 & (6) & 11 & (9) & 4 & (3) & 0.100 & c \\
\hline Induced delivery & 58 & $(25)$ & 47 & $(41)$ & 11 & (9) & $<0.001$ & $\mathrm{~b}$ \\
\hline \multicolumn{9}{|l|}{ Measures } \\
\hline 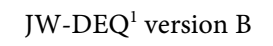 & 53.28 & \pm 28.73 & 64.25 & \pm 27.42 & 42.30 & \pm 25.75 & $<0.001$ & a \\
\hline HADS $^{2}$ anxiety & 2.50 & \pm 2.48 & 2.86 & \pm 2.52 & 2.14 & \pm 2.39 & 0.028 & a \\
\hline
\end{tabular}

${ }^{1}$ The Japanese version of the Wijma Delivery Expectancy/Experience Questionnaire (33 items, scored 0 165); ${ }^{2}$ The Hospital anxiety and depression scale (Anxiety: 7 items, scored $0-21$; Depression: 7 items,

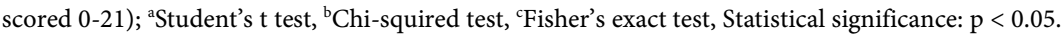


Table 2. Factor loadings of the JW-DEQ version B.

\begin{tabular}{|c|c|c|c|c|c|}
\hline & & $\begin{array}{l}\text { Factor } 1 \\
\text { Fear }\end{array}$ & $\begin{array}{c}\text { Factor } 2 \text { Lack of } \\
\text { positive anticipation }\end{array}$ & $\begin{array}{l}\text { Factor } 3 \\
\text { Isolation }\end{array}$ & $\begin{array}{l}\text { Factor } 4 \\
\text { Riskiness }\end{array}$ \\
\hline 16 & Composed $^{\mathrm{R}}$ & 0.97 & -0.04 & -0.05 & -0.15 \\
\hline 25 & Behave badly & 0.92 & -0.13 & 0.00 & -0.16 \\
\hline 19 & Panic & 0.85 & -0.15 & -0.05 & 0.02 \\
\hline 17 & Relaxed $^{\mathrm{R}}$ & 0.74 & 0.20 & -0.11 & -0.16 \\
\hline 5 & Confident $^{\mathrm{R}}$ & 0.72 & 0.02 & 0.06 & -0.04 \\
\hline 22 & Self-confidence ${ }^{R}$ & 0.69 & 0.13 & 0.06 & 0.05 \\
\hline 27 & Lose control of myself & 0.68 & -0.15 & 0.17 & -0.12 \\
\hline 24 & Pain & 0.66 & 0.16 & -0.07 & -0.08 \\
\hline 10 & Independent $\mathrm{t}^{\mathrm{R}}$ & 0.61 & 0.12 & -0.05 & -0.01 \\
\hline 4 & Strong ${ }^{\mathrm{R}}$ & 0.60 & 0.14 & 0.11 & -0.14 \\
\hline 8 & Weak & 0.53 & -0.07 & 0.31 & 0.12 \\
\hline 2 & Frightful & 0.50 & 0.09 & 0.09 & 0.22 \\
\hline 23 & Trust $^{\mathrm{R}}$ & 0.46 & 0.10 & 0.21 & 0.21 \\
\hline 12 & Tense & 0.42 & -0.17 & -0.03 & 0.34 \\
\hline 6 & Afraid & 0.40 & -0.06 & 0.12 & 0.38 \\
\hline 20 & Hopelessness & 0.37 & 0.14 & 0.22 & 0.17 \\
\hline 31 & Dangerous & 0.33 & 0.21 & -0.05 & 0.31 \\
\hline 14 & Proud $^{\mathrm{R}}$ & -0.19 & 0.93 & 0.14 & -0.13 \\
\hline 13 & Glad $^{\mathrm{R}}$ & -0.15 & 0.80 & 0.27 & -0.14 \\
\hline 18 & Happy $^{\mathrm{R}}$ & 0.10 & 0.71 & 0.15 & -0.09 \\
\hline 29 & Natural $^{\mathrm{R}}$ & 0.17 & 0.58 & -0.20 & 0.25 \\
\hline 1 & Fantastic $^{\mathrm{R}}$ & 0.05 & 0.56 & -0.10 & 0.01 \\
\hline 21 & Longing for the child ${ }^{\mathrm{R}}$ & -0.08 & 0.54 & 0.14 & 0.00 \\
\hline 30 & Self-evident ${ }^{R}$ & 0.23 & 0.52 & -0.27 & 0.18 \\
\hline 28 & Enjoyable $^{\mathrm{R}}$ & 0.40 & 0.47 & -0.13 & 0.03 \\
\hline 26 & $\begin{array}{l}\text { Allow my body to take } \\
\text { control }^{\mathrm{R}}\end{array}$ & 0.28 & 0.29 & -0.06 & 0.02 \\
\hline 15 & Abandoned & 0.00 & -0.07 & 0.67 & 0.00 \\
\hline 3 & Lonely & 0.02 & 0.15 & 0.64 & -0.01 \\
\hline 7 & Deserted & 0.16 & 0.03 & 0.64 & -0.07 \\
\hline 11 & Desolate & -0.09 & 0.08 & 0.54 & 0.21 \\
\hline 33 & Child will die & -0.26 & -0.04 & 0.12 & 0.89 \\
\hline 32 & Child will be injured & -0.12 & -0.04 & -0.05 & 0.88 \\
\hline \multirow[t]{2}{*}{9} & $\mathrm{Safe}^{\mathrm{R}}$ & 0.14 & 0.20 & -0.02 & 0.22 \\
\hline & Variance (\%) total & 39.5 & 6.8 & 5.4 & 5.3 \\
\hline
\end{tabular}

Maximum Likelihood Method, Promax rotation. R: Reverse item. 
one according to the Kaiser-Guttman rule [23]. The four factors; "fear, isolation, lack of positive anticipation and riskiness" [10] detected in previous studies were similarly identified among Japanese women in the present study. The cumulative variance explained by these factors was $57.0 \%$. The factor loadings of three items were less than 0.3: "dangerous" (item 31), "allow my body to take control" (item 26) and "safe" (item 9). These items also loaded on more than two factors such as fear, isolation and riskiness. Some of the items in the JW-DEQ version B loaded onto different factors than those in the JW-DEQ version A: "weak" (item 8), "safe" (item 9), "hopelessness" (item 20), "natural" (item 29) and "dangerous" (item 31 ). The four-factor structure was found among both primipara and multipara mothers.

\subsection{Concurrent Validity}

Table 3 presents the results of the Pearson's correlations between the JW-DEQ version $B$ and the HADS anxiety subscale. The total score of the JW-DEQ version B was moderately correlated with the HADS anxiety subscale $(r=0.34, \mathrm{p}<$ $0.001)$, indicating satisfactory concurrent validity.

\subsection{Internal Consistency}

The Cronbach's $\alpha$ of the total JW-DEQ version B was 0.95 . However, the Cronbach's $\alpha$ of the riskiness factor items was only 0.65 (Table 4 ).

\section{Discussion}

In the present study, the Japanese W-DEQ version B (JW-DEQ version B) was developed to assess Japanese mothers' experiences related to fear of childbirth in the postnatal period. The factorial and concurrent validity, as well as the internal consistency (reliability), were explored. The main results indicated that the

Table 3. Pearson's product correlation coefficient(r).

\begin{tabular}{lcccccc}
\hline & $\begin{array}{c}\text { JW-DEQ } \\
\text { version B }\end{array}$ & $\begin{array}{c}\text { Factor 1 } \\
\text { Fear }\end{array}$ & $\begin{array}{c}\text { Factor 2 Lack of positive } \\
\text { anticipation }\end{array}$ & $\begin{array}{c}\text { Factor 3 } \\
\text { Isolation }\end{array}$ & $\begin{array}{c}\text { Factor 4 } \\
\text { Riskiness }\end{array}$ \\
\hline HADS $^{2}$ & 0.34 & 0.32 & 0.25 & 0.22 & $* *$ & 0.35 \\
\end{tabular}

${ }^{*} \mathrm{p}<0.05,{ }^{* *} \mathrm{p}<0.001$; ${ }^{1}$ The Wijma Delivery Expectancy/Experience Questionnaire Japanese version B (33 items: 0 - 165 scores); ${ }^{2}$ The Hospital Anxiety and Depression Scale anxiety subscale (7 items: 0 - 21 scores).

Table 4. Cronbach's $\alpha$.

\begin{tabular}{cc}
\hline & Cronbach's $\alpha$ \\
\hline$J^{2}-\mathrm{DEQ}^{1}$ version B total & 0.95 \\
Factor 1: Fear & 0.93 \\
Factor 2: Lack of positive anticipation & 0.87 \\
Factor 3: Isolation & 0.74 \\
Factor 4: Riskiness & 0.65 \\
\hline
\end{tabular}

${ }^{1}$ The Wijma Delivery Expectancy/Experience Questionnaire Japanese version B (33 items: 0 - 165 scores). 
JW-DEQ version $B$ has four factors: fear, lack of positive anticipation, isolation and riskiness. The JW-DEQ version B was also found to have good concurrent validity with the HADS anxiety scale and high internal consistency for the total scale. However, some of the items only weakly described one of the factors as indicated by the low factor loadings $(<0.3)$; therefore, reconsideration of the items may be necessary in the future.

The JW-DEQ version B has the same factor structure as version A: fear, lack of positive anticipation, isolation and riskiness [14]. In addition, both primipara and multipara groups have the same factor structure. With regard to other language versions of the $\mathrm{W}-\mathrm{DEQ}$ version $\mathrm{B}$, we could not find any research paper reporting the results of a factor analysis.

In previous studies, the factorial validity was rarely investigated. Wiklund et al. (2008) reported having the same four factors as the W-DEQ version B, which is consistent with this Japanese version [11]. Kukulu et al. (2016) compared four and six factor structures by means of confirmatory factor analysis, demonstrating that the six factor model is the best fit [12]. However, the six factors were originally selected by the Kaiser-Guttman rule (eigenvalue $>1$ ), which is not recommended for determining the number of factors [24] for the following reasons; First, this method is recommended for the principal component analysis (PCA) case and not for the EFA. Second, this method can lead to subjective decisions and third, it has a high tendency to overestimate the numbers [24]. Although a scree plot has a limitation in terms of its subjectivity, it is considered more suitable than the Kaiser method [25]. In addition, the data in the present study did not have six factors greater than one of the EFA eigenvalues. Thus, the four factor solution based on the scree plot method is considered valid in this study. Therefore, the present study is the first to confirm the psychometric properties of the JW-DEQ version B and find support for the factorial validity.

It is interesting that some items of the JW-DEQ version B loaded onto different factors than those of the JW-DEQ version A [14]: "weak" (item 8), "safe" (item 9), "hopelessness" (item 20), "natural" (item 29) and "dangerous" (item 31). "Weak" (item 8) and "hopelessness" (item 20) loaded onto the fear factor in version $B$, whereas in version A they loaded onto the isolation factor [14]. "Natural" (item 29) loaded onto lack of positive anticipation in version B but fear in version A. "Safe" (item 9) loaded onto riskiness in version B but lack of positive anticipation in version A. Finally, "dangerous" (item 31) loaded onto fear in version B but riskiness in version A. These results suggest that some mothers may interpret their fear about childbirth differently before and after delivery, possibly reflecting a gap between expectation and experience before/after childbirth. Mothers in a Japanese cultural context expect their forthcoming childbirth to be adequately supported by family and professionals. "Weak" (item 8) and "hopelessness" (item 20) may indicate a mother's concern about being in a situation without sufficient support from others. However, these interpretations may change from an external expectation of support from others (version A) to internal self-reflection on one's own vulnerability when facing the reality of la- 
bour and uncontrollable situations (version B).

In addition, "natural birth" is described both as "a birth without any medical intervention and "birth achieved by a mother's spontaneous power in collaboration with the unborn baby", which is deemed an optimal childbirth by Japanese mothers [26] [27]. Although women might be afraid if they have to undergo a medical intervention before delivery (version A), they may interpret "natural" as achieving a successful outcome as a result of their own confidence and strength. Two items did not obtain factor loadings of $>0.3$ : allow my body to take control (item 26) and safe (item 9). These items may also be ambiguous in terms of interpretation. Considering that these items cross-loaded onto various factors in both version A and B [14] (Table 2), they may not clearly explain any of the factors in either version. However, we retained them for the following reasons: First, the sample might be inadequate because it was small and the study was conducted in only one clinic. Second, to confirm the suitability of the JW-DEQ version $B$ as a standard measure of fear of childbirth, it should be compared with the scores of the $\mathrm{W}-\mathrm{DEQ}$ version $\mathrm{B}$ in other countries.

Furthermore, the riskiness factor of the JW-DEQ version B comprises only three items ("child will die" [item 31], "child will be injured" [item 33] and "safe" [item 9]). A factor that does not include at least three items will have insufficient degrees of freedom for defining a latent factor [28]. Although the factor meets Costello and Osborne's criterion, it might only weakly explain riskiness because the factor loading for safe (item 9) is low (0.22) [28].

Regarding concurrent validity, the JW-DEQ version B showed a weak correlation with the HADS anxiety subscale, which was expected (Table 3). The concurrent validity was therefore confirmed. Furthermore, because the Cronbach's $\alpha$ value of the total 33-item scale was above 0.7 , the internal consistency of the JW-DEQ version B is good. However, the Cronbach's $\alpha$ of the riskiness factor was lower than the acceptance criterion (0.7), which again may be because of the poor factor loading of safe (item 9).

Our study has some limitations. First, it was conducted in only one setting in Tokyo and the women enrolled were healthy. Compared with the 2010 national data [29], the age and educational background of our sample was higher. Therefore, the findings should be interpreted with caution. The inclusion of younger women who live in other districts would be necessary to ensure greater generalizability of the results. Although our participants were relatively healthy, they included women with a broad range of ages, educational backgrounds and delivery modes. Second, the riskiness factor is assumed to be unstable because it only contains three items and item 9 (safe) had poor factor loadings. Considering that the riskiness factor was weak in both the Japanese and the English W-DEQ [10] [14], future studies may need to reconsider the factor items. Third, confirmatory factor analysis was not conducted due to the limited sample size. Further examination of the JW-DEQ version B among a larger population with more diverse demographic characteristics is required.

Although several limitations stated above, this is the first study which revealed 
the evidence regarding validity and reliability of the JW-DEQ version $\mathrm{B}$. The scale would be helpful for health care providers to assess woman's birth experience properly. However, we must point out the need for some caution when using the JW-DEQ version B. First, using the total score of the 33 items or employing semi-structured modelling to form the latent variables of factors instead of using each factor scores is recommended, because the factors revealed in this study were correlated. Second, our finding that some items loaded onto different factors in versions A and B suggests that they should be regarded as totally different measures. Therefore, in contrast to some earlier studies we recommend that the scores of version A and version B should not be compared. Future studies aimed at reconsidering the items in the Swedish, English and Japanese versions in collaboration with the original Swedish and Norwegian researchers would facilitate the development of a more validated and standardized measure.

\section{Conclusion}

The findings of the present study support the initial validity and reliability of the JW-DEQ version B among Japanese mothers as a scale for measuring fear of childbirth in the postnatal period.

\section{Acknowledgements}

The authors would like to express their deepest appreciation to all participants, translators and medical professionals for their cooperation. Special thanks to Dean Toshinori Kitamura of the Kitamura Institute of Mental Health Tokyo for his continuous supervision.

\section{Funding Statement}

This study was funded by a MEXT/JSPS KAKENHI Grant-in Aid for Challenging Exploratory Research (23660058). This research was done while the author (M.T) was a doctoral student at Department of Midwifery and Women's Health, Graduate School of Medicine, the University of Tokyo (Japan)

\section{References}

[1] Wijma, K., Wijma, B. and Zar, M. (1998) Psychometric Aspects of the W-DEQ: A new Questionnaire for the Measurement of Fear of Childbirth. Journal of Psychosomatic Obstetrics and Gynaecology, 19, 84-97. https://doi.org/10.3109/01674829809048501

[2] Eriksson, C., Jansson, L. and Hamberg, K. (2006) Women's Experiences of Intense Fear Related to Childbirth Investigated in a Swedish Qualitative Study. Midwifery, 22, 240-248. https://doi.org/10.1016/j.midw.2005.10.002

[3] Lundgren, I. (2005) Swedish Women's Experience of Childbirth 2 Years after Birth. Midwifery, 21, 346-354. https://doi.org/10.1016/j.midw.2005.01.001

[4] Verreault, N., Da Costa, D., Marchand, A., Ireland, K., Banack, H., Dritsa, M., et al. (2012) PTSD Following Childbirth: A Prospective Study of Incidence and Risk Factors in Canadian Women. Journal of Psychosomatic Research, 73, 257-263.

https://doi.org/10.1016/j.jpsychores.2012.07.010 
[5] American Psychiatric Association (2013) Diagnostic and Statistical Manual of Mental Disorders. 5th Edition (DSM-5), American Psychiatric Publishing.

[6] Allen, S. (1998) A Qualitative Analysis of the Process, Mediating Variables and Impact of Traumatic Childbirth. Journal of Reproductive and Infant Psychology, 16, 107-131. https://doi.org/10.1080/02646839808404563

[7] Söderquist, J., Wijma, B., Thorbert, G. and Wijma, K. (2009) Risk Factors in Pregnancy for Posttraumatic Stress and Depression after Childbirth. An International Journal of Obstetrics and Gynaecology, 116, 672-680. https://doi.org/10.1111/j.1471-0528.2008.02083.x

[8] Takegata, M., Haruna, M., Matsuzaki, M., Shiraishi, M., Okano, T. and Severinsson, E. (2015) Does Antenatal Fear of Childbirth Predict Postnatal Fear of Childbirth? A Study of Japanese Women. Open Journal of Nursing, 5, 144-152. https://doi.org/10.4236/ojn.2015.52017

[9] Fenaroli, V. and Saita, E. (2013) Fear of Childbirth: A Contribution to the Validation of the Italian Version of the Wijma Delivery Expectancy/Experience Questionnaire (WDEQ). Testing, Psychometrics, Methodology in Applied Psychology, 20, 131-154.

[10] Fenwick, J., Gamble, J., Nathan, E., Bayes, S. and Hauck, Y. (2009) Pre- and Postpartum Levels of Childbirth Fear and the Relation-Ship to Birth Outcomes in a Cohort of Australian Women. Journal of Clinical Nursing, 18, 667-677. https://doi.org/10.1111/j.1365-2702.2008.02568.x

[11] Wiklund, I., Edman, G., Ryding, E.L. and Andolf, E. (2008) Expectation and Experiencesof Childbirth in Primiparae with Caesar-Ean Section. BJOG, 115, 324-331. https://doi.org/10.1111/j.1471-0528.2007.01564.x

[12] Kurucku, O., Bulut, O. and Kukulu K. (2016) Psychometric Evaluation of the Wijma Delivery Expectancy/Experience Questionnaire Version B. Health Care for Women International, 37, 550-567. https://doi.org/10.1080/07399332.2014.943838

[13] Wild, D., Grove, A., Martin, M., Eremenco, S., McElroy, S. and Lorenz, A. (2005) Principles of Good Practice for the Translation and Cultural Adaptation Process for Patient Reported Outcomes (PRO) Measures: Report of the IPOR Task Force for Translation and Cultural Adaptation. Value in Health, 8, 94-104. https://doi.org/10.1111/j.1524-4733.2005.04054.x

[14] Takegata, M., Haruna, M., Matsuzaki, M., Shiraishi, M., Murayama, R., Okano, T., et al. (2013) Translation and Validation of the Japanese Version of the Wijma Delivery Expectancy/Experience Questionnaire Version A. Nursing Health Sciences, 15, 326-332. https://doi.org/10.1111/nhs.12036

[15] Rubin, R. (1961) Puerperal Change. Nursing Outlook, 9, 753-755.

[16] Zigmond, A.S. and Snaith, R.P. (1983) The Hospital Anxiety and Depression Scale. Acta Psychiatrica Scandinavica, 67, 361-370. https://doi.org/10.1111/j.1600-0447.1983.tb09716.x

[17] Kitamura, T. (1993) Hospital Anxiety and Depression Scale (HADS). Seishinkashindangaku, 4, 371-372. (In Japanese)

[18] Spielberger, C.D., Gorsuch, R.L., Lushene, R., Vagg, P.R. and Jacobs, G.A. (1983) Manual for the State-Trait Anxiety Inventory. Consulting Psychologists Press, Palo Alto.

[19] Miller-Keane and O’Toole, M. (2003) Miller-Keane Encyclopedia \& Dictionary of Medicine, Nursing \& Allied Health. Revised Reprint, 7th Edition, Elsevier, Amsterdam.

[20] Devellis, R. (2012) Scale Development Theory and Applications. Sage Publications, 
New York

[21] Cohen, J. (1988) Statistical Power Analysis for the Behavioral Sciences. Lawlence Elsbaum Associate Publishers, Hillsdale.

[22] Nunnally, J.C. and Bernstein, I.R. (1994) Psychometric Theory. McGraw-Hill, New York.

[23] Kaiser, H.F. (1960) The Application of Electronic Computers to Factor Analysis. Educational and Psychological Measurement, 20, 141-151. https://doi.org/10.1177/001316446002000116

[24] Zwick, W.R. and Velicer, W.F. (1986) Comparison of Five Rules for Determining the Number of Components to Retain. Psychology Bulletin, 99, 432-442. https://doi.org/10.1037/0033-2909.99.3.432

[25] Ledesma, R.D. and Varelo-Mora, P. (2007) Determining the Number of Factors to Retain in EFA: An Easy to Use Computer Program for Carrying out Parallel Analysis. Practical Assessment, Research \& Evaluation, 12, 1-11.

[26] Ichikawa, K. and Kamada, T. (2009) How Does a Midwive's Care Effect Mother's Valuable Childbirth Experience?-The Research through CBE Scale. BoseiEisei, 50, 79-87. (In Japanese)

[27] Morsbach, G. (1983) Attitudes and Experiences of Japanese Mothers Concerning the Period of Childbirth. Psychologia, 26, 73-85.

[28] Costello, A. and Osborne, J. (2005) Best Practices in Exploratory Factor Analysis: Four Recommendations for Getting the Most from Your Analysis. Practical Assessment, Research \& Evaluation, 10, 1-9.

[29] Ministry of Health, Labor \& Welfare. (2010) Longitudinal Survey of Newborns in the 21 st Century (2010 Cohort). Tokyo. http://www.e-stat.go.jp/SG1/estat/List.do?lid=000001117995

Submit or recommend next manuscript to SCIRP and we will provide best service for you:

Accepting pre-submission inquiries through Email, Facebook, LinkedIn, Twitter, etc. A wide selection of journals (inclusive of 9 subjects, more than 200 journals)

Providing 24-hour high-quality service

User-friendly online submission system

Fair and swift peer-review system

Efficient typesetting and proofreading procedure

Display of the result of downloads and visits, as well as the number of cited articles

Maximum dissemination of your research work

Submit your manuscript at: http://papersubmission.scirp.org/

Or contact ojn@scirp.org 